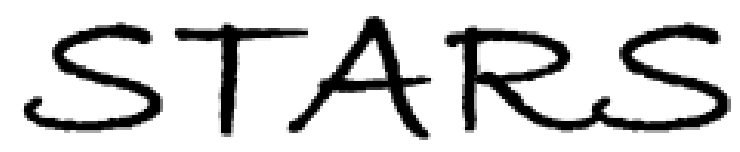

University of Central Florida

STARS

$1-1-1994$

\title{
Laser Demonstration Of Neodymium-Doped Strontium Chlorovanadate
}

\author{
Laura D. DeLoach \\ Stephen A. Payne \\ Bruce H. T. Chai \\ University of Central Florida \\ George Loutts \\ University of Central Florida
}

Find similar works at: https://stars.library.ucf.edu/facultybib1990

University of Central Florida Libraries http://library.ucf.edu

This Article is brought to you for free and open access by the Faculty Bibliography at STARS. It has been accepted for inclusion in Faculty Bibliography 1990s by an authorized administrator of STARS. For more information, please contactSTARS@ucf.edu.

\section{Recommended Citation}

DeLoach, Laura D.; Payne, Stephen A.; Chai, Bruce H. T.; and Loutts, George, "Laser Demonstration Of Neodymium-Doped Strontium Chlorovanadate" (1994). Faculty Bibliography 1990s. 1023.

https://stars.library.ucf.edu/facultybib1990/1023

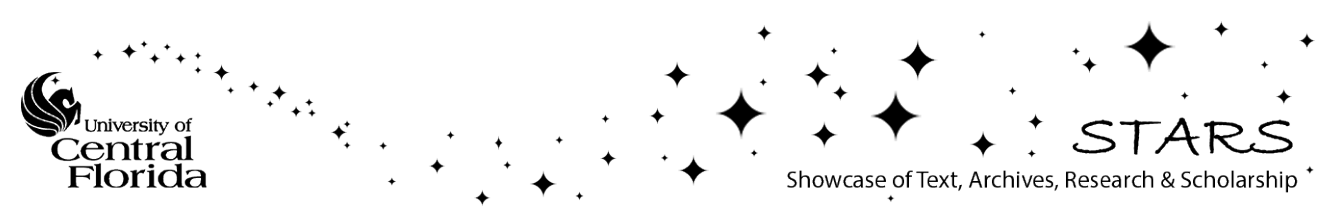




\section{Laser demonstration of neodymium- doped strontium chlorovanadate}

Cite as: Appl. Phys. Lett. 65, 1208 (1994); https://doi.org/10.1063/1.112072

Submitted: 15 February 1994 . Accepted: 22 June 1994 . Published Online: 04 June 1998

Laura D. DeLoach, Stephen A. Payne, Bruce H. T. Chai, and George Loutts

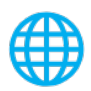

\section{ARTICLES YOU MAY BE INTERESTED IN}

Ytterbium-doped apatite-structure crystals: A new class of laser materials Journal of Applied Physics 76, 497 (1994); https://doi.org/10.1063/1.357101

Crystal-field splitting of energy levels of rare-earth ions $\mathrm{Dy}^{3+}\left(4 \mathrm{f}^{9}\right)$ and $\mathrm{Yb}^{3+}\left(4 \mathrm{f}^{13}\right)$ in $\mathrm{M}$ (II) sites in the fluorapatite crystal $\mathrm{Sr}_{5}\left(\mathrm{PO}_{4}\right)_{3} \mathrm{~F}$

Journal of Applied Physics 83, 1009 (1998); https://doi.org/10.1063/1.366790

Site-selective spectroscopy and determination of energy levels in $\mathrm{Eu}^{3+}$-doped strontium fluorophosphate

Journal of Applied Physics 78, 2456 (1995); https://doi.org/10.1063/1.360099

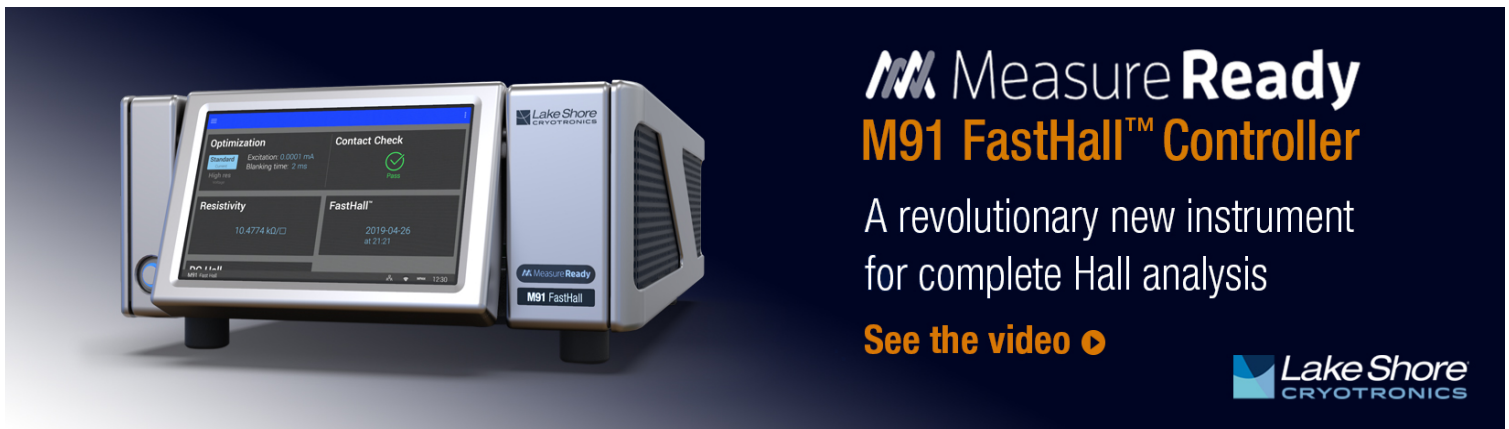




\title{
Laser demonstration of neodymium-doped strontium chlorovanadate
}

\author{
Laura D. DeLoach and Stephen A. Payne \\ Lawrence Livermore National Laboratory, University of California, P.O. Box 5508, Livermore, \\ California 94550
}

Bruce H. T. Chai and George Loutts

Center for Research in Electro-Optics and Lasers (CREOL), University of Central Florida, Orlando, Florida 32826

(Received 15 February 1994; accepted for publication 22 June 1994)

\begin{abstract}
$\mathrm{Nd}: \mathrm{Sr}_{5}\left(\mathrm{VO}_{4}\right)_{3} \mathrm{Cl}$ has been successfully lased using a Ti:sapphire pump laser operating at $810 \mathrm{~nm}$. A slope efficiency of $52 \%$ for the $1.065 \mu \mathrm{m}$ laser line and a lasing threshold of only a few tens of milliwatts have been measured. These favorable results are comparable to another Nd-doped vanadate apatite, $\mathrm{Sr}_{5}\left(\mathrm{VO}_{4}\right)_{3} \mathrm{~F}$. A brief survey of the spectroscopy of $\mathrm{Nd}^{3+}$ in $\mathrm{Sr}_{5}\left(\mathrm{VO}_{4}\right)_{3} \mathrm{Cl}$, $\mathrm{Sr}_{5}\left(\mathrm{VO}_{4}\right)_{3} \mathrm{~F}$, and $\mathrm{Ca}_{5}\left(\mathrm{VO}_{4}\right)_{3} \mathrm{~F}$ reveals properties which suggest the vanadate-based apatite crystals as a whole may represent a useful new class of Nd-laser hosts.
\end{abstract}

In the late 1960 s, Nd-doped $\mathrm{Ca}_{5}\left(\mathrm{PO}_{4}\right)_{3} \mathrm{~F}$, known as fluorapatite (FAP), emerged as a high gain laser medium that was suitable for flash-lamp pumping. ${ }^{1,2}$ The contemporaneously developed $\mathrm{Nd}$ :YAG $\left(\mathrm{Y}_{3} \mathrm{Al}_{5} \mathrm{O}_{12}\right)$ laser material, possessing an emission cross section of only about one-half that of FAP, eventually came to dominate laser technology due to its superior thermal and mechanical properties. ${ }^{3}$ The Nd:YAG emission did in fact have adequate transition strength for most laser requirements, and therefore the greater mechanical strength proved to be a more significant factor. More recently, diode lasers have developed into viable pump sources for applications requiring high efficiency and compact laser designs. Some applications in particular require systems with low threshold powers in order to minimize the pump power consumption. These criteria are generally satisfied by laser crystals with a large product of the emission cross section and emission lifetime, and a strong absorption peak with adequate bandwidth at the output wavelength of the diode. While Nd:YAG and Nd:YLF $\left(\mathrm{LiYF}_{4}\right)$ are presently the most commonly employed $\mathrm{Nd}$ lasers, ${ }^{4}$ considerable effort has gone into developing $\mathrm{Nd}: \mathrm{YVO}_{4}$ as an alternative, low threshold diode-pumped laser medium. $\mathrm{Nd}: \mathrm{YVO}_{4}$ offers attractive performance parameters as well as higher Nd-doping levels, which can serve to minimize the required thickness of the gain medium., ${ }^{5,6}$ Nevertheless, $\mathrm{Nd}: \mathrm{YVO}_{4}$ has crystal growth problems which although showing recent and dramatic improvement, have greatly limited the size of high quality single crystals available. It is interesting that now, as a result of the reduced thermal loading associated with diode pumping (compared to flash-lamp pumping), Nd:FAP is again a favorable candidate for lasers requiring a low laser threshold, in spite of its inferior thermal properties. ${ }^{7,8}$

The use of the apatite hosts for laser ions has steadily evolved over the last few decades. Westinghouse scientists initially investigated the phosphate and silicate apatite analogs and found that the structure provided a favorable site for the $\mathrm{Nd}^{3+}$ and $\mathrm{Ho}^{3+}$ activator ions. ${ }^{1,9}$ More recently, our group has explored the potential of the $\mathrm{Yb}^{3+}$ ion in the phosphate apatites and discovered that $\mathrm{Yb}$-doped $\mathrm{Ca}_{5}\left(\mathrm{PO}_{4}\right)_{3} \mathrm{~F}$ and $\mathrm{Sr}_{5}\left(\mathrm{PO}_{4}\right)_{3} \mathrm{~F}$ exhibit excellent laser performance. ${ }^{10-12}$ We have subsequently expanded our research to include several apa- tite crystals based on the vanadate species. Thus far, we have reported the laser results of two promising new vanadatebased apatites: $\mathrm{Yb}: \mathrm{Sr}_{5}\left(\mathrm{VO}_{4}\right)_{3} \mathrm{~F}$ and $\mathrm{Nd}: \mathrm{Sr}_{5}\left(\mathrm{VO}_{4}\right)_{3} \mathrm{~F}^{13,14}$ The $\mathrm{Nd}: \mathrm{Sr}_{5}\left(\mathrm{VO}_{4}\right)_{3} \mathrm{~F}$ demonstrates excellent spectroscopic features and laser performance. It also offers the advantage that high quality boules of several cubic centimeters are readily grown by conventional Czochralski crystal growth. We believe this new apatite crystal will become a major contender for lowthreshold diode-pumped $\mathrm{Nd}$ laser systems. In this letter, we describe the spectroscopic properties of Nd-doped $\mathrm{Ca}_{5}\left(\mathrm{VO}_{4}\right)_{3} \mathrm{~F}, \mathrm{Sr}_{5}\left(\mathrm{VO}_{4}\right)_{3} \mathrm{~F}$, and $\mathrm{Sr}_{5}\left(\mathrm{VO}_{4}\right)_{3} \mathrm{Cl}$. We also report $\mathrm{Nd}: \mathrm{Sr}_{5}\left(\mathrm{VO}_{4}\right)_{3} \mathrm{Cl}$ has been grown and lased successfully for the first time.

The crystal growth and preparation of the starting materials for the fluorovanadates and fluorophosphates have been previously described in Refs. 14-17. In this study, crystals were doped with 1-2 wt $\% \mathrm{Nd}$ in the melt. We give a summary of the melting points and the Nd distribution coefficients we have determined in Table I with general comments about their crystal quality and growth. Generally, the fluorovanadates melt at lower temperatures than the fluorophosphates, and the Nd distribution coefficient tends to be smaller for the larger host metal ions and for the chlorides versus the fluorides. The most favorable hosts for crystal growth are $\mathrm{Ca}_{5}\left(\mathrm{PO}_{4}\right)_{3} \mathrm{~F}, \mathrm{Sr}_{5}\left(\mathrm{PO}_{4}\right)_{3} \mathrm{~F}$, and $\mathrm{Sr}_{5}\left(\mathrm{VO}_{4}\right)_{3} \mathrm{~F}$, while $\mathrm{Ca}_{5}\left(\mathrm{VO}_{4}\right)_{3} \mathrm{~F}$ and $\mathrm{Ba}_{5}\left(\mathrm{PO}_{4}\right)_{3} \mathrm{~F}$ growth runs produce only low quality samples. Apparently, $\mathrm{Sr}_{5}\left(\mathrm{VO}_{4}\right)_{3} \mathrm{Cl}$ can be grown from a melt (with substantial vaporization of $\mathrm{SrCl}_{2}$ ), while $\mathrm{Ca}_{5}\left(\mathrm{PO}_{4}\right)_{3} \mathrm{Cl}$ must be obtained from a $\mathrm{CaCl}_{2}$ flux. The attempts to grow $\mathrm{Ba}_{5}\left(\mathrm{VO}_{4}\right)_{3} \mathrm{~F}$ single crystals have been unsuccessful.

We have collected room-temperature absorption and emission data of the new Nd-doped vanadate apatites from which adequate single crystals were obtained for spectroscopic study: $\mathrm{Ca}_{5}\left(\mathrm{VO}_{4}\right)_{3} \mathrm{~F}, \mathrm{Sr}_{5}\left(\mathrm{VO}_{4}\right)_{3} \mathrm{~F}$, and $\mathrm{Sr}_{5}\left(\mathrm{VO}_{4}\right)_{3} \mathrm{Cl}$. The absorption spectra were obtained using a Perkin Elmer Lambda 9 spectrophotometer and are plotted in Fig. 1. Both $\mathrm{Sr}_{5}\left(\mathrm{VO}_{4}\right)_{3} \mathrm{~F}$ and $\mathrm{Sr}_{5}\left(\mathrm{VO}_{4}\right)_{3} \mathrm{Cl}$ were oriented and scanned with polarized light (since apatitc crystals arc optically anisotropic), whereas the lack of higher optical quality for $\mathrm{Ca}_{5}\left(\mathrm{VO}_{4}\right)_{3} \mathrm{~F}$ prevented us from specifying its orientation. The polarized spectra in Fig. 1 correspond to the favorable pump and ex- 
TABLE I. Selected crystal growth properties of apatite crystals $(\mathrm{CZ}=\mathrm{Czochralski})$.

\begin{tabular}{|c|c|c|c|}
\hline Crystal & $\begin{array}{c}\text { Melting } \\
\text { point }\left({ }^{\circ} \mathrm{C}\right)\end{array}$ & $\begin{array}{l}\text { Nd distribution } \\
\text { coefficient }\end{array}$ & Comments \\
\hline $\mathrm{Ca}_{5}\left(\mathrm{VO}_{4}\right)_{3} \mathrm{~F}$ & 1510 & 0.44 & $\begin{array}{c}\text { CZ; not single phase; } \\
\text { high scatter losses prevent } \\
\text { optically orienting bulk crystal }\end{array}$ \\
\hline $\mathrm{Sr}_{5}\left(\mathrm{VO}_{4}\right)_{3} \mathrm{~F}$ & 1650 & 0.25 & $\begin{array}{l}\text { CZ; low-loss crystals; } \\
\sim 3 \times 15 \mathrm{~cm} \text { boules }\end{array}$ \\
\hline $\mathrm{Ba}_{5}\left(\mathrm{VO}_{4}\right)_{3} \mathrm{~F}$ & (1570) & $\ldots$ & $\begin{array}{c}\text { Decomposes to } \mathrm{Ba}_{5}\left(\mathrm{VO}_{4}\right)_{2} \\
\text { and } \mathrm{BaCl}_{2}\end{array}$ \\
\hline $\mathrm{Sr}_{5}\left(\mathrm{VO}_{4}\right)_{3} \mathrm{Cl}$ & 1550 & 0.05 & $\begin{array}{c}\mathrm{CZ} \text {; high vaporization of } \mathrm{SrCl}_{2} \\
\text { component; boule cracking } \\
\text { limited size of oriented crystal } \\
\text { to } 5 \times 5 \times 15 \mathrm{~mm}^{3}\end{array}$ \\
\hline $\mathrm{Ca}_{5}\left(\mathrm{PO}_{4}\right)_{3} \mathrm{~F}$ & 1700 & 0.52 & $\begin{array}{l}\text { CZ; low-loss crystal; } \\
\sim 3 \times 15 \mathrm{~cm} \text { boules }\end{array}$ \\
\hline $\mathrm{Sr}_{5}\left(\mathrm{PO}_{4}\right)_{3} \mathrm{~F}$ & 1810 & 0.33 & $\begin{array}{l}\text { CZ; low-loss crystal; } \\
\sim 3 \times 15 \mathrm{~cm} \text { boules }\end{array}$ \\
\hline $\mathrm{Ba}_{5}\left(\mathrm{PO}_{4}\right)_{3} \mathrm{~F}$ & 1730 & $\cdots$ & $\begin{array}{l}\mathrm{CZ} \text {; small, partially opaque } \\
\text { boule; clear regions of a few } \\
\text { cubic millimeters }\end{array}$ \\
\hline $\mathrm{Ca}_{5}\left(\mathrm{PO}_{4}\right)_{3} \mathrm{Cl}$ & 1200 (flux) & $\cdots$ & $\begin{array}{c}\mathrm{CaCl}_{2} \text { flux; incongruently melting; } \\
\text { millimeter-sized, } \\
\text { low-quality crystals }\end{array}$ \\
\hline
\end{tabular}

traction orientation of the apatite laser crystal, $E \|_{c}$, which is the unique symmetry axis for these structures. Normal to the $c$ axis the absorption pump band, $\sim 810 \mathrm{~nm}$, is reduced by a factor of 1.9 in the fluorovanadate and by 1.6 in the chlorovanadate. The unpolarized emission spectra of these Nddoped apatites were obtaincd by cxciting the samples near $575 \mathrm{~nm}$ with a Nd:YAG pumped dye laser and measuring the

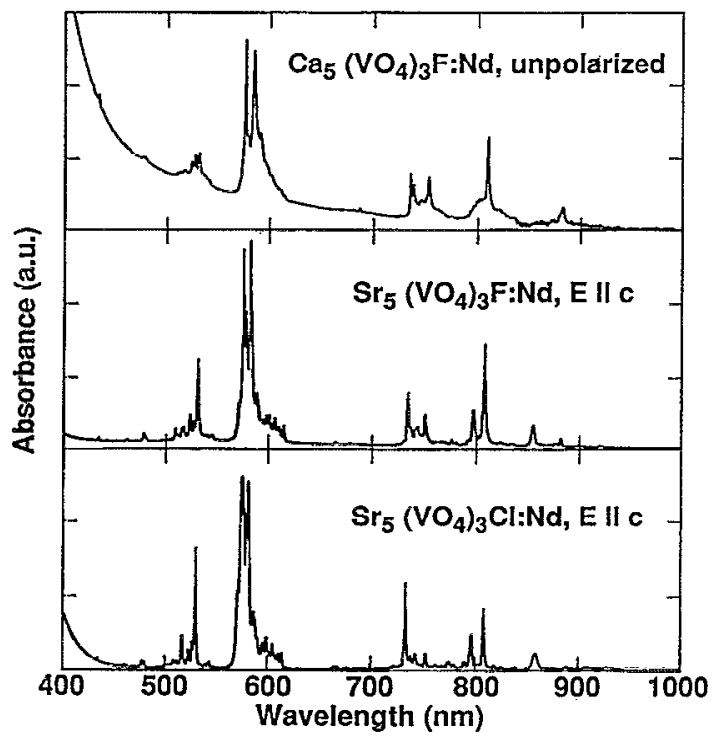

FIG. 1. The absorption spectra of the Nd-doped vanadate apatites. For comparison, the absorbance at the $810 \mathrm{~nm}$ peak height and the thickness for each sample are as follows: $\mathrm{Ca}_{5}\left(\mathrm{VO}_{4}\right)_{3} \mathrm{~F} A=0.26, t=0.07 \mathrm{~cm} ; \mathrm{Sr}_{5}\left(\mathrm{VO}_{4}\right)_{3} \mathrm{~F}$ $A=1.56, t=0.38 \mathrm{~cm} ; \mathrm{Sr}_{5}\left(\mathrm{VO}_{4}\right)_{3} \mathrm{Cl} A=0.67, t=0.19 \mathrm{~cm}$. dispersed signal with a grating monochromator and an S-1 photomultiplier tube. These spectra are plotted in Fig. 2 in the region of the prominent $1065 \mathrm{~nm}$ emission peak. Also, the emission decay rate which has been measured for these hosts with a transient digitizing oscilloscope is indicated on each spectral plot. Employing the Füchtbauer-Ladenburg formula which requires an emission spectrum and radiative lifetime (we assume the measured emission lifetime), we

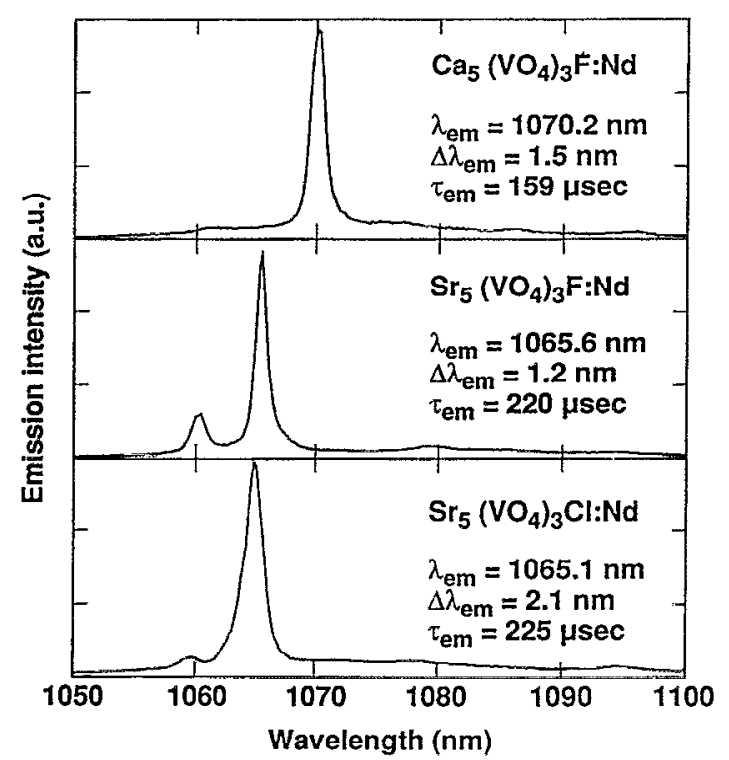

FIG. 2. Unpolarized emission spectra of the ${ }^{4} F_{3 / 2}$ to ${ }^{4} F_{11 / 2}$ transition of $\mathrm{Nd}^{3+}$ in the vanadate apatites. 


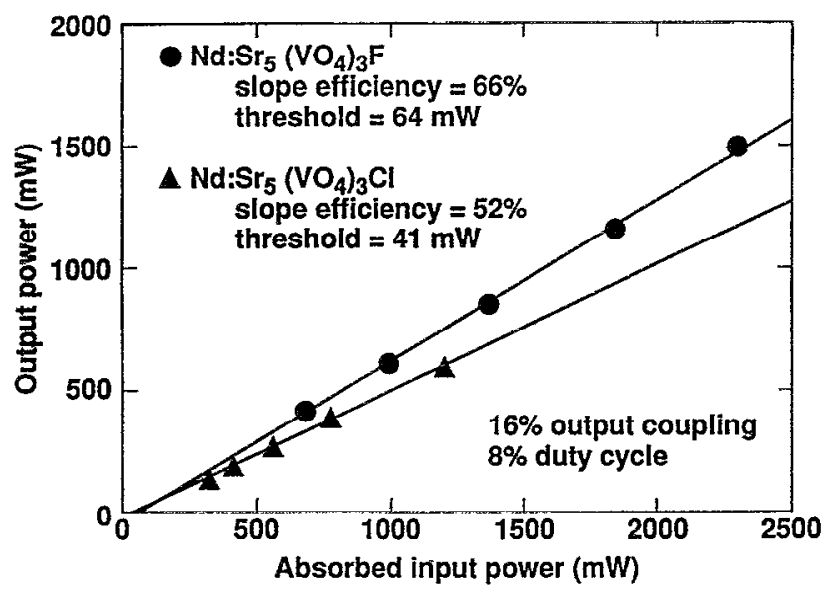

FIG. 3. The laser efficiency data for $\mathrm{Nd}: \mathrm{Sr}_{5}\left(\mathrm{VO}_{4}\right)_{3} \mathrm{~F}$ and $\mathrm{Nd}: \mathrm{Sr}_{5}\left(\mathrm{VO}_{4}\right)_{3} \mathrm{Cl}$.

have determined the effective emission cross section, $\sigma_{\mathrm{em}}$, of the $1065 \mathrm{~nm}$ band within $\pm 15 \%$ to be $5.0 \times 10^{-19} \mathrm{~cm}^{2}$ in $\mathrm{Nd}: \mathrm{Sr}_{5}\left(\mathrm{VO}_{4}\right)_{3} \mathrm{~F}$. We observe that the lifetimes of $\mathrm{Nd}^{3+}$ in $\mathrm{Sr}_{5}\left(\mathrm{VO}_{4}\right)_{3} \mathrm{~F}$ and in $\mathrm{Sr}_{5}\left(\mathrm{VO}_{4}\right)_{3} \mathrm{Cl}$ are similar, $\sim 220 \mu$ s, while $\mathrm{Nd}^{3+}$ in $\mathrm{Ca}_{5}\left(\mathrm{VO}_{4}\right)_{3} \mathrm{~F}$ is $159 \mu \mathrm{s}$. The bandwidth of the laser line feature in these hosts is also indicated and is between 1 and $2 \mathrm{~nm}$ for each apatite. Using the $\sigma_{\mathrm{em}}$ of $\mathrm{Nd}$ in $\mathrm{Sr}_{5}\left(\mathrm{VO}_{4}\right)_{3} \mathrm{~F}$, we have estimated a value for $\mathrm{Sr}_{5}\left(\mathrm{VO}_{4}\right)_{3} \mathrm{Cl}$ using the ratio of the emission linewidths at 1065 and the ratio of the squared refractive indices, and we obtain $2.8 \times 10^{-19} \mathrm{~cm}^{2}$.

Crystals of both $\mathrm{Nd}: \mathrm{Sr}_{5}\left(\mathrm{VO}_{4}\right)_{3} \mathrm{~F}$ and $\mathrm{Nd}: \mathrm{Sr}_{5}\left(\mathrm{VO}_{4}\right)_{3} \mathrm{Cl}$ have been lased in a standard experimental arrangement which has been described in detail previously. ${ }^{10}$ The 2-4$\mathrm{mm}$-thick laser crystal is centrally situated in a $10 \mathrm{~cm}$ concentric cavity employing an output coupling of $16 \%$ and a Ti:sapphire laser at $810 \mathrm{~nm}$ as the pump source. By comparing the output power to the absorbed input power [fraction adsorbed is $99 \%$ for an antireflection-coated $\mathrm{Sr}_{5}\left(\mathrm{VO}_{4}\right)_{3} \mathrm{~F}$ and $74 \%$ for an uncoated $\left.\mathrm{Sr}_{5}\left(\mathrm{VO}_{4}\right)_{3} \mathrm{Cl}\right]$, we obtain the slope efficiency data which are plotted in Fig. 3. The lower slope efficiency of $52 \%$ in Nd:Sr $5\left(\mathrm{VO}_{4}\right)_{3} \mathrm{Cl}$ compared to $66 \%$ in $\mathrm{Sr}_{5}\left(\mathrm{VO}_{4}\right)_{3} \mathrm{~F}$ may be a reflection of higher scattering losses. Scattering losses of only $0.3 \% / \mathrm{cm}$ have been measured in $\mathrm{Sr}_{5}\left(\mathrm{VO}_{4}\right)_{3} \mathrm{~F}^{14}$ and although no determinations have been made for the chlorovanadate the optical quality appears to be lower. Some parasitic absorption loss from impurities may be present in both laser crystals.

A comparison of the spectroscopic and laser properties for the Nd-doped vanadate apatites shows a marked similarity to the favorable properties generally arising from the apatite structure crystals. These include highly polarized spectra with strong absorption and emission bands for light polarized along the $c$ axis, which provide an effective means for both pumping and extracting energy. Among these vanadate analogs, the positions and widths of the emission lines vary from one host to another. The calcium fluorovanadate has an emission peak at $1070 \mathrm{~nm}$ and a bandwidth (FWHM) of $1.5 \mathrm{~nm}$. The strontium analogs both peak at $1065 \mathrm{~nm}$, with the chlorovanadate having a greater bandwidth of $2.1 \mathrm{~nm}$ compared with $1.2 \mathrm{~nm}$ in the strontium fluorovanadate. The greater bandwidth of the chlorovanadate is estimated to produce a lower effective emission cross section of $2.8 \times 10^{-19} \mathrm{~cm}^{2}$ compared to the measured value of $5.0 \times 10^{-19} \mathrm{~cm}^{2}$ in the strontium fluorovanadate. The laser performance data in Fig. 3 indicate that the $\mathrm{Nd}: \mathrm{Sr}_{5}\left(\mathrm{VO}_{4}\right)_{3} \mathrm{~F}$ has a slope efficiency of $66 \%$ with a $16 \%$ output coupling, compared to a lower slope efficiency of $52 \%$ for $\mathrm{Nd}: \mathrm{Sr}_{5}\left(\mathrm{VO}_{4}\right)_{3} \mathrm{Cl}$. This difference may be due to inferior quality of the $\mathrm{Sr}_{5}\left(\mathrm{VO}_{4}\right)_{3} \mathrm{Cl}$ crystal compared to the $\mathrm{Sr}_{5}\left(\mathrm{VO}_{4}\right)_{3} \mathrm{~F}$ sample that was lased.

In conclusion, we find that the vanadate-based apatites define a new class of Nd lasers which should serve usefully in diode-pumped systems. The crystals we have studied include the calcium and strontium fluorovanadates and the strontium chlorovanadate. Of these, the two strontium analogs were of adequate crystal quality for characterization of the laser performance. We have measured the slope efficiencies in $\mathrm{Nd}: \mathrm{Sr}_{5}\left(\mathrm{VO}_{4}\right)_{3} \mathrm{~F}$ and $\mathrm{Nd}: \mathrm{Sr}_{5}\left(\mathrm{VO}_{4}\right)_{3} \mathrm{Cl}$ to be $66 \%$ and $52 \%$, respectively. The best laser candidate from this class appears to be the strontium fluorovanadate, but the strontium chlorovanadate may prove to be of similar value with the availability of higher quality crystals.

We wish to thank Larry Smith for the laser performance measurements and Gary Wilke for some of the spectroscopy determinations. We also express our appreciation to Eberhard Prochnow (retired), Ron Vallene, and Peter Thelin for the fabrication and finishing of the samples. This work was performed under the auspices of the Department of Energy by Lawrence Livermore National Laboratory under Contract W-7405-ENG-48. The work at CREOL was supported by ARPA Contract No. N00014-93-1-0664 and the Florida High Technology and Industrial Council.

${ }^{1}$ R. C. Ohlmann, K. B. Steinbruegge, and R. Mazelsky, Appl. Opt. 7, 905 (1968).

${ }^{2}$ Z. M. Bruk, Yu. K. Voron'ko, G. V. Maksimova, V. V. Osiko, A. M. Prokhorov, K. F. Shpilov, and I. A. Shcherbakov, JETP Lett. 8, 221 (1968).

${ }^{3}$ J. K. Neeland and V. Evtuhov, Phys. Rev. 156, 224 (1967).

${ }^{4} \mathrm{~J}$. A. Caird and S. A. Payne, in Handbook of Laser Science and Technology, Supplement 1: Lasers (Chemical Rubber, Boca Raton, FL, 1991), p. 3.

${ }^{5}$ T. S. Lomheim and L. G. DeShazer, J. Appl. Phys. 49, 5517 (1978).

${ }^{6}$ R. A. Fields, M. Birnbaum, and C. L. Fincher, Appl. Phys. Lett. 51, 1885 (1987).

${ }^{7}$ Z. Shao, Y. Chen, and J. C. Bergquist, Chinese Phys. 11, 391 (1991).

${ }^{8}$ X. X. Zhang, G. B. Loutts, M. Bass, and B. H. T. Chai, Appi. Phys. Lett. 64, 10 (3 Jan. 94).

${ }^{9}$ K. B. Steinbruegge, T. Henningsen, R. H. Hopkins, R. Mazelsky, N. T. Melamed, E. P. Reidel, and G. W. Roland, Appl. Opt. 11, 999 (1972).

${ }^{10}$ S. A. Paync, I. K. Smith, L. D. DeLoach, W. L. Kway, J. B. Tassano, and W. F. Krupke, IEEE J. Quantum Electron. QE-30, 170 (1994).

${ }^{11}$ L. D. DeLoach, S. A. Payne, L. K. Smith, W. L. Kway, and W. F. Krupke, J. Opt. Soc. Am. B 11, 269 (1994).

${ }^{12}$ L. D. DeLoach, S. A. Payne, B. H. T. Chai, W. F. Krupke, L. K. Smith, W. L. Kway and J. B. Tassano, in OSA Proceedings on Advanced Solid-State Lasers (OSA, Washington, DC, 1993), Vol. 15, p. 188.

${ }^{13}$ S. A. Payne, L. D. DeLoach, L. K. Smith, W. L. Kway, J. B. Tassano, W. F. Krupke, B. H. T. Chai, and G. Loutts, J. Appl. Phys. 76, 497 (1994).

${ }^{14}$ B. H. T. Chai, G. Loutts, X. X. Zhang, S. A. Payne, W. F. Krupke, L. D. DeLoach, and L. K. Smith, Opt. Lett. (to be published).

${ }^{15}$ M. P. Glazyrin, S. I. Alyamovskii, A. A. Ivakin, and A. V. Kruzhalov, Russ. J. Inorg. Chem. 21, 1306 (1976).

${ }^{16}$ L. H. Brixner, J. Solid State Chem. 1, 185 (1970).

${ }^{17}$ A. M. Korovkin, Yu. M. Lagunenko, A. M. Morozov, and P. P. Feofilov, Growth Cryst. 12, 242 (1984). 